\title{
The Influence of the External and Internal Business Environment on the Marketing Strategy and Their Impact on the Marketing Performance
}

\author{
Hery Erdi \\ Faculty of Economics, Jakarta Islamic University, Jakarta, Indonesia \\ R. Bambang. BC \\ Krakatau College of Economics, Bandar Lampung, Indonesia
}

\begin{abstract}
One of the challenges faced by palm oil companies in Indonesia is how they can maintain and increase sales of palm oil at a price and acceptable manner. For this reason, one of the efforts the companies must take is to adopt an effective marketing strategy that is in line with the company's business objectives. Marketing strategy has a strategic role, however, research on the factors influencing marketing strategy adoption and its impact on marketing performance is still relatively limited. This study aims to examine the influence of the external and the internal environment on the adoption of marketing strategy and their impact on marketing performance. This study used a survey method and a questionnaire to collect data relevant to the research objectives. The samples involved were 125 oil palm companies located in South Lampung Province of Indonesia. The findings indicate that both the external and the environment have a significant positive effect on marketing strategy and performance. The finding is in line with the notion that the business environment, marketing strategy, and marketing performance are positively correlated. The findings also indicate that product, price, promotion and distribution-based marketing strategies have a positive effect on the marketing performance. The findings imply the importance for companies in aligning their adopted marketing strategy with the external and internal environmental aspects in an effort to reach their goals effectively.
\end{abstract}

Keywords: business environment, marketing strategy, marketing performance, Indonesian palm oil companies

DOI: $10.7176 / \mathrm{EJBM} / 13-7-06$

Publication date: April $30^{\text {th }} 2021$

\section{Introduction}

The main objective of a company's operations in general is to increase its profits from one period to the next, because an increase in revenue will increase the sustainability of the company. The increase in profit is highly dependent on the firm performance through its functional performance, such as marketing, finance, and human resources performance. The combination of these functional performance will determine the firm performance on the whole. In addition, business performance is influenced by the business environment, as well as by the human resources quality working in the company. These businees environment includes economic, social and culture, government policy, law, economic globalization, and use of technology (O'Cass \& Julian, 2003).

One important aspect of Indonesia's economy is the plantation sector. The plantation sector is one of the importance sources of the country's economy. The government's policy of shifting the export orientation from the gas to non-oil exports as a source of foreign exchange has been supported by the existence of the plantation sector in Indonesia (Mahlia et al., 2001). Therefore, the demands and challenges faced by the oil sector in the future are getting worse as the structural conditions of public support and its ecological environment have changed. Therefore, the company must have the right strategy in order to survive and even improve their performance. Such conditions have forced many companies to develop strategies in accordance with their environmental conditions in an effort to improve company performance in order to compete in the market (McCarthy et al., 2012).

The literature suggests that the right formulation and implementation of company strategy is able to influence the success of a company in the market. Therefore, the management need to develop apropiate strategies to enhance their performance and goals (Appiah-Adu et al., 2001). Sharma (2004) states that marketing strategy is an important strategy to be adopted by the company to increase their competitiveness in the era of globalization and liberalization. According to the researcher, marketing strategy as a planned fundamental tool for achieving company goals by developing a sustainable competitive advantage. This means that the marketing strategy is able to assist the company in building their activities to improve their performance dand goals.

The literature also emphasizes the importance for companies to combine marketing strategies with various strategies related to other management functions to produce a better organizational performance. In particular, Indris and Primiana (2015) suggest companies to take advantage of environmental conditions to increase 
organizational access to take advantage of opportunities generated by the environment, and work around environmental conditions to develop organizational capabilities in adapting to emerging threats. A good understanding of the environment will have an impact on improving marketing performance. Companies must adapt the marketing strategy adopted to the changing environment and assign appropriate resources to support the chosen marketing strategy. The company's ability to identify environmental changes, adoption of appropriate marketing performance, and support adequate resources has the potential to improve marketing performance. One of the challenges faced by palm oil companies in Indonesia is how they can maintain and increase sales of palm oil at a price and acceptable manner (McCarthy et al., 2012). This study aims to investigate the influence of the external and internal environment on the marketing strategy and performance of palm oil companies in Indonesia.

\section{Literature Review and Hypothesis Development}

\subsection{Business environment}

The business environment is still a factor that academics and industry practitioners often overlook. In fact, a positive environment will have a positive impact on company performance. Having good organizational resources and ecosystems will certainly allow the company to operate well and will achieve success in the long term (Dionco-Adetayo \& Adetayo, 2003). According to Sridhar et al. (2016), companies need to understand the concept of the business environment and what factors must be in it. Furthermore, Sridhar et al. argues that the business environment is the sum total of all individuals, institutions, and other forces that are outside the control of the company; however, these factors can affect the company's performance and sustainability. The factors that shape this business environment include suppliers, competitors, consumer groups, media, government, customers, economic conditions, market conditions, investors, technology, trends, and various other institutions outside the company. As an illustration, an increase in tax has the potential to decrease the number of purchases. Thus, the company must re-establish the selling price for profitable and safe as a result of these tax changes. Even though the company has no involvement in the increase in taxes, the company still has to adapt to survive or use the opportunity to make a profit. A similar conception was put forward by Gasparotti (2009) which suggests the business environment as something or specific activities that are taking place within or surrounding the company. In other words, the business environment is any factors that are within or outside the business organization that affect business activities.

The literature emphasizes the importance of company leaders in understanding the business environment because the business environment can have an impact on the success and development of the company's business. The business environment can have a positive or negative impact on the success and development of the company's business. Companies can benefit from understanding the business environment, including enabling the company to identify available business opportunities; utilize existing resources efficiently and effectively; ready to face environmental changes; assist companies in designing future plans; and take advantage of the business environment to assist companies in improving performance (Banahene et al., 2016).

The literature generally divides the business environment into two, namely the external environment and the internal environment. The external environment refers to factors outside the company that have the potential to influence the company's activities, while the internal environment refers to factors that are within the organization and have a direct influence on the company's activities (Al-Hawary \& Al-Hamwan, 2017) . Indris and Primiana (2015) explain that the external environment can be divided into two, namely the social environment and the work environment. Social environment refers to general factors that are not directly related to the company's business activities. These factors include, among others, economic strength, technological strength, legal-political power, and socio-cultural power. Meanwhile, the work environment refers to factors that can directly affect the company's business activities. These factors include government policies, suppliers, competitors, customers and creditors. Indris and Primiana further explained that the external environment can also be classified into two; namely the macro environment and the micro environment. The macro environment includes political-legal, economic, socio-cultural and technological factors; while the micro environment includes creditors, suppliers, competitors, and customers. Meanwhile, factors included as the internal environment include factors such as employees, finance, production technology, and marketing.

\subsection{Marketing strategy}

A literature review shows that marketing is an important function that must be considered by a company. This marketing process ensures that every product from the company can reach consumers. Therefore, companies need to build specific strategies to carry out marketing activities and ensure that the company gets profits according to the expected targets (El-Ansary, 2006). According to Azizi et al. (2009), marketing strategy can be referred to as an explanation of the goals that companies must achieve with marketing efforts. Thus, the marketing strategy is dependent on business goals. As an illustration, if the goal to be achieved is to adopt a wider market, then one form of marketing strategy is to introduce the company's products to new market 
segments. In other words, marketing strategy includes anything a company must do to achieve both marketing goals and business goals. As an illustration, companies must inform consumers about the products or services offered and also the factors that differentiate the products and services that companies offer from other products and services. Meanwhile, according to Koksal and Ozgul, (2007), marketing strategy can be understood as an organizational strategy that combines all its marketing objectives into one comprehensive plan. A good marketing strategy must be taken based on market research and focus on the right product mix to achieve maximum profit potential and sustain business. Simply put, a marketing strategy is a strategy designed to promote goods or services and of course to generate profits for the company.

The literature emphasizes the importance of companies to make careful and precise considerations when making marketing strategies. Without an effective marketing strategy, efforts to attract consumers will be unfocused and the use of resources becomes inefficient, making it difficult to achieve organizational goals, namely to gain profit and business growth (Shaw, 2012). According to Cavusgil and Zou (1994), the focus of marketing strategy is to ensure that the products and services provided by the company will be able to meet customer needs and develop long-term and profitable relationships with these customers. To achieve this, companies need to create flexible marketing strategies that can respond to changes in customer perceptions and demands. It can also help companies to identify new markets that are worthy of being targeted. An effective marketing strategy allows companies to get various benefits such as more efficient distribution of goods, building and enhancing brand images, and creating products that sell well in the market.

Furthermore, the literature emphasizes that companies need to develop an effective marketing strategy as a long-term approach to selling the company's products or services. This is based on the understanding that an effective marketing strategy allows a company to grow its business in a sustainable manner and connect with customers which in turn will be successful in the long term. In building a marketing strategy, of course, companies need a deep understanding of the market, competitors, and of course their customers. Some of the steps that companies need to take in building a marketing strategy include determining the customers they want to target, identifying the products to be marketed, conducting research on the competition map, determining unique propositions for the products offered, determining the resources needed, and determining marketing methods. appropriate (White and Griffith, 1997; Jenkins, 1992). In order for marketing activities to run well, a good marketing strategy is needed too. According to Boso et al., 2018), there are four minimum requirements that must be met in building a marketing strategy, namely the company must be able to determine the most appropriate place to carry out marketing activities; the company must also provide products needed and wanted by consumers or marketing targets; companies must set prices that are reasonable and also not burdensome to consumers; companies must design the most appropriate and appropriate promotional activities.

\subsection{Marketing performance}

A literature review shows that performance can be understood in various ways. For example, performance can be referred to as the end result of certain work operations that are carried out in a planned place and at specific times by employees and the organization; performance as a result of work, both in quantity and quality, of an employee in handling his duties in accordance with the obligations that have been given; or the results obtained from the ability and motivation of a person in carrying out their work or duties (Akdogan \& Durak, 2016). In marketing, performance is a measure of achievement obtained from the overall marketing activity process of an organization. Marketing performance can also be viewed as a concept used in measuring the extent to which market performance can be achieved by a product that has been produced by the company. In addition, marketing performance can also be referred to as a measure used to measure the success of the strategies that companies use in marketing their products in the market (Deng et al., 2016).

According to Pimenta da Gama (2011), marketing performance is the factors used to measure the impact of the marketing strategy implemented by the company. Marketing strategy is always directed to produce good marketing performance as well as good financial performance. In this case, there are three indicators that can be used to measure marketing performance, namely company effectiveness, sales growth, and relative profit growth. In addition, marketing performance is formed by three indicators, namely sales growth, customer growth and sales volume. Meanwhile, Akdogan \& Durak (2016) argue that marketing performance can be measured or assessed from various indicators such as the level of sales, increased revenue, number of customers, or from other indicators that describe the extent to which the level of success of marketing a product or service from a company. Of course the success of marketing performance is also determined by the strategy used by the company to compete with its competitors. Marketing performance is declared successful if the sales data states that the number of product sales increases, the number of customers increases, income increases, the market is wider, and the product is increasingly recognized by consumers or the public.

A different opinion was expressed by Eusebio et al. (2006) which suggests that marketing performance can be measured using six categories; namely financial measures, market sizes, consumer behavior measures, intermediary consumer measures, direct customer measures, and innovation measures. The same thing was 
conveyed by Nwokah (2009) who explained that marketing performance can be measured based on six categories; namely finance, competitive markets, consumer behavior, and customer intermediaries, direct customers, and innovation.

\section{Research Methodology}

3.1 Research design

This study aims to investigate the business environment on the marketing strategy and performance of oil palm companies in South Sumatra Province, Indonesia. In this study, the business environment acts as an independent variable, marketing performance acts as the dependent variable, and marketing strategy acts as a mediator variable. This study uses a questionnaire as a tool to collect data relevant to the variables studied. The questionnaires were distributed directly to leaders of oil palm companies in South Sumatra Province, Indonesia. The sample involved in this study were 125 companies. This research took place from September 2019 to January 2020. The study used structural equation modeling to analyze the data collected.

\subsection{Research variables}

Referring to various sources (Wheelen and Hunger, 2008; David, 2008), this study considers that the external environment is a multidimensional construct. In this study, the external environment was measured using six indicators. All external environmental indicators are measured using a five-point Likert scale ranging from 1 (strongly disagree) to 5 (strongly agree). Based on the Wheelen and Hunger (2008) and David (2008) work, this study considers that the internal environment is a multidimensional construct. In this study, the internal environment is measured using six indicators. All internal environmental indicators are measured using a fivepoint Likert scale ranging from 1 (strongly disagree) to 5 (strongly agree). Following Cravens and Piercy (2012) dan Schultz (2003), and Grant (2007), this study considers that marketing strategy is a multidimensional construct. In this study, the marketing strategy was measured using seven indicators. All indicators of marketing strategy are measured using a five-point Likert scale ranging from 1 (strongly disagree) to 5 (strongly agree). For marketing performance, this study considers that marketing performance is a multidimensional construct (Kotler and Keller, 2008; Moorman, 2004). In this study, marketing performance is measured using four indicators. All marketing performance indicators are measured using a five-point Likert scale ranging from 1 (strongly disagree) to 5 (strongly agree).

\subsection{Research model and formulation of hypotheses}

This study aims to investigate the influence of the business environment on marketing strategy and performance of Indonesian palm oil companies. Based on the literature review as stated in the previous chapter, this study builds a conceptual framework as shown in Figure 1. Based on this conceptual framework, this study proposes working hypotheses as follows.

Hypothesis 1

The external environment has a significant positive effect on the marketing strategy

Hypothesis 2

The external environment has a significant positive effect on marketing performance Hypothesis 3

The internal environment has a significant positive effect on marketing strategy

Hypothesis 4

The internal environment has a significant positive effect on marketing performance

Hypothesis 5

Marketing strategy has a significant positive effect on marketing performance 


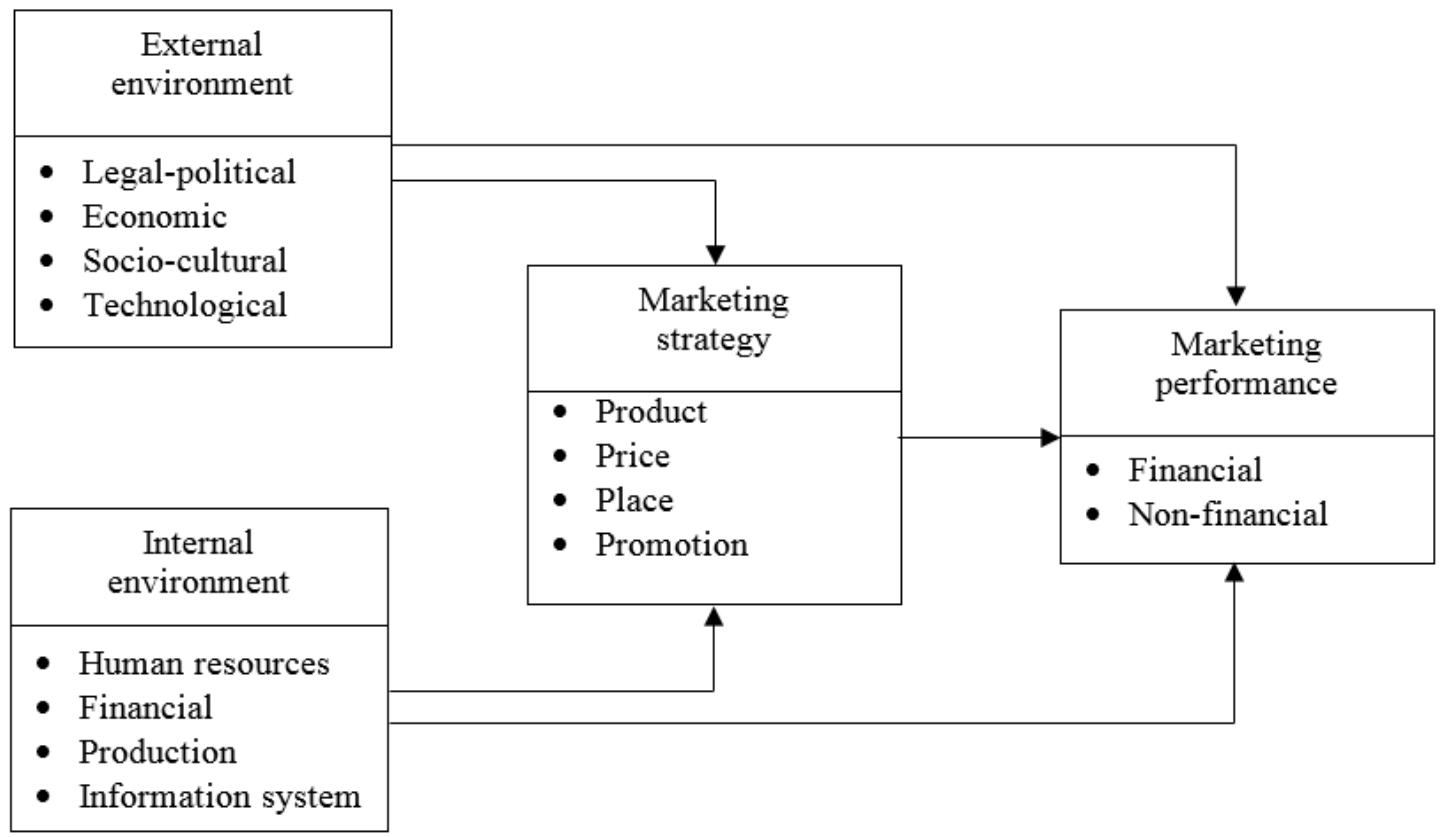

Figure 1

The conceptual framework proposed in this study

\section{Results and Discussion \\ 4.1 Validity and Reliability Test}

This study conducted validity and reliability tests to ensure that the instruments used in the study were valid and reliable. This study uses the Corrected item-total correlation (CITC) in the validity test and uses the Cronbach alpha value in the research instrument reliability test. By using an alpha of 0.05 and 125 degrees of freedom, this study determined that an item would be declared valid if the item had a CITC greater than 0.174 and the research instrument would be declared reliable if the Cronbach alpha value obtained was greater than 0.60.

For the external environment construct, the results of the analysis yielded Cronbach's alpha values ranging from 0.74 to 0.88 while the CITC values ranged from 0.41 to 0.77 . This finding confirms that all items used to measure the external environmental construct are valid considering that the resulting CITC is greater than 0.174. Meanwhile, the resulting Cronbach alpha value was greater than 0.60; indicates that the instrument used to construct the external environment is reliable. For the internal environment construct, the results of the analysis produced Cronbach's alpha values ranging from 0.71 to 0.82 while the CITC values ranged from 0.33 to 0.76. This finding confirms that all items used to measure the internal environmental construct are valid considering the resulting CITC is greater than 0.174. Meanwhile, the resulting Cronbach alpha value was greater than 0.60 ; indicates that the instrument used to construct the internal environment is reliable.

For the marketing strategy construct, the analysis resulted in Cronbach's alpha values ranging from 0.75 to 0.81 while the CITC values ranged from 0.40 to 0.73 . These findings confirm that all items used to measure the marketing strategy construct are valid considering that the resulting CITC is greater than 0.174. Meanwhile, the resulting Cronbach alpha value was greater than 0.60; indicates that the instrument used to construct the marketing strategy is reliable. For the marketing performance construct, the analysis resulted in Cronbach's alpha values ranging from 0.80 to 0.89 while the CITC values ranged from 0.43 to 0.79 . These findings confirm that all items used to measure the marketing performance construct are valid considering that the resulting CITC is greater than 0.174. Meanwhile, the resulting Cronbach alpha value was greater than 0.60; indicates that the instrument used to construct marketing performance is reliable.

\subsection{Descriptive analysis}

This section describes the descriptive analysis for the four constructs studied, namely the external environment, the internal environment, the marketing strategy and the marketing strategy of the oil palm companies in South Lampung province. This study considers four dimensions to measure the external environmental variables of an organization, namely legal and political aspects, economic conditions, socio-cultural aspects, and technological development aspects. The analysis results show that; the mean score for legal and political aspects was 3.83 with a standard deviation of 0.85 ; the mean score for aspects of economic conditions was 4.26 with a standard deviation of 0.68 ; the mean score for the socio-cultural aspect was 3.62 with a standard deviation of 0.74 ; and the mean score for aspects of technological development is 3.58 with a standard deviation of 0.89 . Furthermore, 
this study considers four dimensions to measure organizational internal environmental variables, namely aspects of human resources, financial resources, production technology, and information systems. The analysis results show that; the mean score for the human resource aspect was 3.86 with a standard deviation of 0.89 ; the mean score for the aspect of financial resources was 4.19 with a standard deviation of 0.96 ; the mean score for the aspect of production technology is 3.53 with a standard deviation of 0.92 ; and the mean score for aspects of information systems is 4.24 with a standard deviation of 0.96 .

For marketing strategy variables, this study considers four dimensions to measure the external environmental variables of the organization, namely product strategy, price strategy, promotion strategy and distribution strategy. The analysis results show that; the mean score for the product strategy was 3.76 with a standard deviation of 0.97 ; the mean score for the pricing strategy was 4.07 with a standard deviation of 1.02; the mean score for the promotion strategy was 3.51 with a standard deviation of 0.93 ; and the mean score for the distribution strategy was 3.74 with a standard deviation of 0.96. Furthermore, this study considers two dimensions to measure marketing performance variables, namely financial performance and non-financial performance. The analysis results show that; The mean score for financial performance was 4.15 with a standard deviation of 0.92 and the mean score for non-financial was 3.93 with a standard deviation of 0.91 .

\subsection{Hypothesis testing}

The purpose of this study was to examine the simultaneous relationship between the business environment, marketing strategy and marketing performance of oil palm companies in South Lampung Province, Indonesia. Table 1 summarizes the results of the structural model test of the simultaneous relationship between the three constructs.

The first hypothesis of this study is about the relationship between the external environment of the organization and the marketing performance of oil palm companies in South Lampung Province. This study proposes a hypothesis that the external environment of the organization has a positive influence on the marketing performance of oil palm companies in South Lampung Province. The results of the analysis, as shown in Table 1, show that the external environment of the organization has a significant positive effect on the marketing performance of oil palm companies in South Lampung Province $(\beta=0.37 ; p<0.01)$. Thus the first hypothesis is supported. Furthermore, this study proposes a hypothesis that the external environment of the organization has a positive influence on the marketing strategies of oil palm companies in South Lampung Province. The results of the analysis show that the external environment of the organization has a significant positive effect on the marketing strategies of oil palm companies in South Lampung Province $(\beta=0.35 ; p<0.01)$. Thus the second hypothesis is supported.

Table 1

The results of the simultaneous relationship test between business environment, marketing strategy and marketing performance

\begin{tabular}{llll}
\hline & Relationship & SRW. & CR. \\
\hline External environment & $\longrightarrow$ Marketing performance & 0,37 & 6,44 \\
External environment & $\longrightarrow$ Marketing strategy & 0,35 & 6,37 \\
Internal environment & $\longrightarrow$ Marketing performance & 0,29 & 4,31 \\
Internal environment & $\longrightarrow$ Marketing strategy & 0,44 & 7,44 \\
Marketing strategy & $\longrightarrow$ Marketing performance & 0,27 & 4,22 \\
\hline External environment & $\longrightarrow$ Legal-political & 0,87 & \\
External environment & $\longrightarrow$ Economic & 0,71 & \\
External environment & $\longrightarrow$ Socio-cultural & 0,89 & \\
External environment & $\longrightarrow$ Technological & 0,84 & \\
Internal environment & $\longrightarrow$ Human resources & 0,78 & \\
Internal environment & $\longrightarrow$ Financial resources & 0,83 & \\
Internal environment & $\longrightarrow$ Production technology & 0,79 & \\
Internal environment & $\longrightarrow$ Information system & 0,71 & \\
\hline Marketing strategy & $\longrightarrow$ Product & 0,73 & \\
Marketing strategy & $\longrightarrow$ Price & 0,81 & \\
Marketing strategy & $\longrightarrow$ Promotion & 0,75 & \\
Marketing strategy & $\longrightarrow$ Place & 0,78 & \\
\hline Marketing performance & $\longrightarrow$ Financial performance & 0,84 & \\
Marketing performance & $\longrightarrow$ Non-financial performance & 0,84 & \\
\hline
\end{tabular}

The third hypothesis of this study is about the relationship between the internal environment of the organization and the marketing performance of oil palm companies in South Lampung Province. This study proposes a hypothesis that the organization's internal environment has a positive influence on the marketing performance of oil palm companies in South Lampung Province. The analysis results, as shown in Table 1, 
found that the internal environment of the organization has a significant positive effect on the marketing performance of oil palm companies in South Lampung Province $(\beta=0.29 ; p<0.05)$. Thus the third hypothesis is supported. Furthermore, this study proposes a hypothesis that the internal environment of the organization has a positive influence on the marketing strategies of oil palm companies in South Lampung Province. The results of the analysis show that the internal environment of the organization has a significant positive effect on the marketing strategies of oil palm companies in South Lampung Province $(\beta=0.44 ; p<0.01)$. Thus the fourth hypothesis is supported. Finally, this study proposes a hypothesis that marketing strategies have a positive influence on the marketing performance of oil palm companies in South Lampung Province. The results of the analysis, as shown in Table 1, show that the marketing strategy has a significant positive effect on the marketing performance of oil palm companies in South Lampung Province $(\beta=0.27 ; p<0.05)$. Thus the fifth hypothesis is supported.

The findings of this study confirm that the external environment of the organization has a significant positive effect on the marketing strategy adopted and the improvement of the marketing performance of oil palm companies in South Lampung Province. This finding warns the marketing of oil palm companies in South Lampung Province that the external environment of the organization is an important factor that must be considered in developing the marketing strategy that will be adopted. In other words, oil palm companies in South Lampung Province need to align the marketing strategies they adopt with four aspects of the external environment; namely legal-political aspects, national economic conditions, socio-culture prevailing in the community, and global technological developments. A good external organizational environment will contribute positively to the marketing strategy adopted, which in turn can improve marketing performance.

Furthermore, this study found that the internal environment of the organization has a significant positive effect on the marketing strategy adopted and the improvement of the marketing performance of oil palm companies in South Lampung Province. This finding warns the marketing of oil palm companies in South Lampung Province that the internal environment of the organization is an important factor that must be considered in developing the marketing strategy that will be adopted. In other words, oil palm companies in South Lampung Province need to align the marketing strategies they adopt with four aspects of the internal environment; namely aspects of human resources, financial resources, production technology, and information systems. These four aspects of the internal environment must be conditioned to always be in a good condition because they contribute positively to the adopted marketing strategy, which in turn can improve marketing performance.

Finally, this study found that the marketing strategy has a significant positive effect on improving the marketing performance of oil palm companies in South Lampung Province. This finding implies that if the oil palm companies in South Lampung Province consistently adopt a marketing strategy based on product, price, promotion, and distribution strategies; then it can be an important key that can be used by oil palm companies in South Lampung Province to develop an effective marketing strategy, which in turn will result in higher marketing performance. The findings of this study support an understanding that emphasizes the importance for companies to build an effective marketing strategy considering that marketing strategy is the main strategy for obtaining sustainable organizational performance and creating higher competitiveness.

\section{Conclusion}

The marketing strategy has a strategic role, especially for oil palm companies in South Lampung Province. However, research on the factors that influence the adoption of marketing strategies and their impact on marketing performance is still relatively limited. This study aims to examine the influence of the external and internal environment on the adoption of marketing strategies and their impact on marketing performance in oil palm companies in South Lampung Province. The findings of this study indicate that the legal-political conditions, national economy, socio-culture prevailing in the community, and global technological developments have a significant positive effect on the marketing strategy and performance of oil palm companies in South Lampung Province. This finding is in line with the argument that was built that the external environment, marketing strategy, and marketing performance are positively correlated.

Furthermore, it was found that the condition of human resources, financial resources, production technology, and information systems had a significant positive effect on marketing strategies and performance of oil palm companies in South Lampung Province. This finding is in line with the concept that the internal environment, marketing strategy, and marketing performance are positively correlated with. The findings of this study also indicate that the adoption of product, price, promotion and distribution-based marketing strategies has a positive effect on marketing performance in oil palm companies in South Lampung Province. In other words, the marketing strategies adopted by these companies are able to boost marketing performance, both financial performance and non-financial performance. This finding supports the concept that the marketing strategy is a strategy that can contribute positively to improving organizational performance. 


\section{References}

Appiah - Adu, K., Fyall, A., \& Singh, S. (2001), "Marketing effectiveness and business performance in the financial services industry", Journal of Services Marketing, 15(1), 18-34

Azizi, S., Movahed, S.A., Khah, M.H. (2009), "The effect of marketing strategy and marketing capability on business performance. Case study: Iran's medical equipment sector”, Journal of Medical Marketing, 9 (4), 309-317

Boso, N., Debrah, Y.A. and Amankwah-Amoah, J. (2018), "International marketing strategies of emerging market firms: Nature, boundary conditions, antecedents, and outcomes", International Marketing Review, 35 (2), 202-214

Cavusgil, S.T., and Zou, S. (1994), "Marketing Strategy-Performance Relationship: An Investigation of the Empirical Link in Export Market Ventures", Journal of Marketing, 58 (1), 1-21

El - Ansary, A.I. (2006), "Marketing strategy: taxonomy and frameworks", European Business Review, 18 (4), 266-293

Jenkins, D.P. (1992), "Developing a Marketing Strategy for English Wine in Relation to European Regulations", International Journal of Wine Marketing, 4 (3), 26-34

Koksal, M.H. and Ozgul, E. (2007), "The relationship between marketing strategies and performance in an economic crisis", Marketing Intelligence \& Planning, 25 (4), 326-342

Sharma, B. (2004), "Marketing strategy, contextual factors and performance", Marketing Intelligence \& Planning, 22(2), 128-143

Shaw, E.H. (2012), "Marketing strategy: From the origin of the concept to the development of a conceptual framework", Journal of Historical Research in Marketing, 4 (1), 30-55

White, D.S., and Griffith, D.A. (1997), "Combining corporate and marketing strategy for global competitiveness", Marketing Intelligence \& Planning, 15 (4), 173-178

Akdogan, M.S., and Durak, A. (2016), "Logistic and Marketing Performances of Logistics Companies: A Comparison between Germany and Turkey", Procedia - Social and Behavioral Sciences, Vol. 23524, 576586

Deng, W., Xu, N., Li, H., Liu, F., Shi, Y. (2016), "Difference in Differences in Marketing Performance Measurement", Procedia Computer Science, Vol. 1622019, 275-280

Eusebio, R., Llonch Andreu, J. and Pilar López Belbeze, M. (2006), "Measures of marketing performance: a comparative study from Spain", International Journal of Contemporary Hospitality Management, 18 (2), $145-155$

Nuryakin, and Ardyan, E. (2018), "SMEs' marketing performance: the mediating role of market entry capability", Journal of Research in Marketing and Entrepreneurship, 20 (2), 122-146

Nwokah, N.G. (2009), "Customer - focus, competitor - focus and marketing performance”, Measuring Business Excellence, 13 (3), 20-28

Pimenta da Gama, A. (2011), “An expanded model of marketing performance”, Marketing Intelligence \& Planning, 29 (7), 643-661

Dionco-Adetayo, E.A. and Adetayo, J.O. (2003), "Business Environment Analysis: Globalization Era Imperative For Small Scale Industries", Journal of Social Sciences, 7 (4), 283-292

Sridhar, R., Sachithanandam, V., Mageswaran, T., Purvaja, R., Ramesh, R., Senthil Vel, A., \& Thirunavukkarasu, E. (2016), “A Political, Economic, Social, Technological, Legal and Environmental (PESTLE) approach for assessment of coastal zone management practice in India", International Review of Public Administration, $21(3), 216-232$

Indris, S., and Primiana, I. (2015), "Internal and External Environment Analysis on the Performance of Small and Medium Industries (SMEs) In Indonesia”, International Journal of Scientific \& Technology Research, 4 (4), 188-196

Al-Hawary, S.I.S., and Al-Hamwan, A.M. (2017), "Environmental Analysis and its Impact on the Competitive Capabilities of the Commercial Banks Operating in Jordan", International Journal of Academic Research in Accounting, Finance and Management Sciences, 7 (1), 277-290

Gasparotti, C. (2009), “The Internal and External Environment Analysis of Romanian Naval Industry with SWOT Model", Management \& Marketing, 4 (3), 97-110

Banahene, S., Ahudey, E., Mensah, C. (2016), “Analysis of Macro Environment for Strategy Implementation: What is important to Handicraft Export Organisations in Ghana?", International Journal of Business Management and Economic Research, 7 (3), 632-642

O'Cass, A. and Julian, C. (2003), "Examining firm and environmental influences on export marketing mix strategy and export performance of Australian exporters", European Journal of Marketing, 37 (3/4), 366384 